\title{
Osteoclast formation, survival and morphology are highly dependent on exogenous cholesterol/ lipoproteins
}

\author{
E Luegmayr ${ }^{1}$, H Glantschnig ${ }^{1}$, GA Wesolowski ${ }^{1}$, MA Gentile ${ }^{1}$, \\ JE Fisher ${ }^{1}$, GA Rodan ${ }^{1}$ and AA Reszka*,1 \\ ${ }^{1}$ Molecular Endocrinology \& Bone Biology, Merck \& Co., Inc., West Point, PA, \\ USA \\ * Corresponding author. AA Reszka, Merck Research Laboratories, WP26A- \\ 1000, West Point, PA 19486, USA. Tel.: + 1215652 1410; \\ Fax: + 1215652 4328; E-mail: Alfred_Reszka@merck.com
}

Received 22.8.03; revised 12.11.03; accepted 02.12.03; published online 12.3.04 Edited by Dr A Finazzi-Agro'

\begin{abstract}
Osteoporosis is associated with both atherosclerosis and vascular calcification. No mechanism yet explains the parallel progression of these diseases. Here, we demonstrate that osteoclasts (OCL) depend on lipoproteins to modulate cellular cholesterol levels and that this controls OCL formation and survival. Removal of cholesterol in OCL via high-density lipoprotein or cyclodextrin treatment dose-dependently induced apoptosis, with actin disruption, nuclear condensation and caspase-3 activation. One mechanism linked to the induction of OCL apoptosis was the cell-type-specific failure to induce HMG-CoA reductase mRNA expression, suggesting an absence of feedback regulation of de novo cholesterol biosynthesis. Furthermore, cyclodextrin treatment substantially suppressed essential M-CSF and RANKL-induced survival signaling pathways via Akt, mTOR and S6K. Consistent with these findings, cholesterol delivery via lowdensity lipoprotein (LDL) significantly increased OCL viability. Interestingly, OCLs from the LDL receptor (LDLR) - I- mouse exhibited reduced size and lifespan in vitro. Remarkably, LDLR $+I+$ OCL in lipoprotein-deficient medium phenocopied LDLR $-I-$ OCL, while fusion and spreading of LDLR $-I-$ OCL was rescued when cholesterol was chemically delivered during differentiation. With hyperlipidemia being associated with disease of the vascular system and bone, these findings provide novel insights into the selective lipoprotein and cholesterol dependency of the bone resorbing cell.

Cell Death and Differentiation (2004) 11, S108-S118.

doi:10.1038/sj.cdd.4401399

Published online 12 March 2004
\end{abstract}

Keywords: HDL; LDL; LDL receptor; apoptosis; HMGCR; methyl- $\beta$-cyclodextrin

Abbreviations: OCL, osteoclast; HDL, high-density lipoprotein; LDL, low-density lipoprotein; LDLR, low-density lipoprotein receptor; LPDS, lipoprotein-deficient serum; MBCD, methyl- $\beta$ cyclodextrin; S6, ribosomal protein S6; S6K, ribosomal protein S6 kinase; mTOR, mammalian target of rapamycin

\section{Introduction}

Epidemiological evidence links osteoporosis and cardiovascular disease. Patients with low bone mineral density have a greater risk of mortality in later life, especially from stroke ${ }^{1}$ and cardiovascular disease, ${ }^{2,3}$ a higher plaque score of the artery wall, ${ }^{4-7}$ and higher total cholesterol levels. ${ }^{8,9}$ Although a role for estrogen is suggested, the specific mechanisms connecting osteoporosis and cardiovascular disease remain unknown. Both high low-density lipoprotein (LDL)- and low high-density lipoprotein (HDL)-cholesterol levels were recently found to correlate with low bone mass in postmenopausal women, ${ }^{10}$ suggesting a possible link between plasma lipids and the maintenance of bone mass.

The paradox of osteoporosis accompanied by atherosclerotic calcification has been the subject of several experimental studies. The role of LDL oxidation products and their accumulation in the vessel wall during atherosclerotic lesion formation is well established. ${ }^{11,12}$ Others have shown effects of oxidized lipids on osteoblastic differentiation in vitro. These lipids direct progenitor marrow stromal cells to favor adipogenic over osteogenic differentiation. ${ }^{13,14}$ It was further speculated that oxidized lipids might inhibit osteoblastic activity and bone mineral formation in vivo. ${ }^{15}$ Indeed, a mouse strain with a susceptibility to atherosclerosis (C57BL6) did lose greater bone mass in response to a high fat diet when compared to atherosclerosis-resistant strains. ${ }^{16}$

In contrast to profound inhibitory effects on osteoblast differentiation, ${ }^{13}$ oxidized LDL was found to have no negative effect on the formation of osteoclasts (OCLs) in vitro. ${ }^{17}$ OCLs are multinucleated bone resorbing cells formed from hematopoietic precursors via membrane fusion. Absence of native LDL suppresses OCL formation, and this was attributed to a requirement for cholesterol during the fusion process. ${ }^{17}$ This could be due in part to the very low rate of de novo sterol synthesis in the $\mathrm{OCL},{ }^{18}$ thus necessitating exogenous sources of cholesterol.

In the present study, we examined the role of exogenous cholesterol availability on OCL formation and survival in vitro. Unlike mesenchyme-derived cells (i.e. osteoblasts), OCLs do not respond to rapid cholesterol removal by inducing hydroxymethylglutaryl coenzyme-A reductase (HMGCR), suggesting the lack of this feedback regulation in the cholesterol biosynthesis pathway. Moreover, cholesterol removal by HDL, apolipoprotein A1 (ApoA1) or methyl- $\beta$-cyclodextrin (MBCD) triggers induction of apoptosis and OCL death, whereas similar treatments of osteoblasts were without lasting effect. Consistently, as a result of MBCD-induced cholesterol efflux, we found suppression of antiapoptotic signaling pathways involving Akt and mammalian target of rapamycin (mTOR)/ribosomal protein S6 (S6) kinase (S6K) in OCLs. On the other hand, LDL-mediated cholesterol delivery significantly enhances OCL survival. Furthermore, OCLs 
derived from the LDL receptor (LDLR)-/- mice exhibit abnormal morphology and shortened lifespan versus OCL from LDLR $+/+$ mice. These findings suggest that OCLs depend on lipoproteins to control their cellular cholesterol levels and, in turn, their lifespan.

\section{Results}

\section{Cholesterol efflux from OCLs}

For promoting cholesterol efflux, we used the pharmacological agent MBCD and the physiological cholesterol acceptors HDL and ApoAl. The ability of these agents to stimulate cholesterol efflux from labeled OCLs was validated by the transfer of ${ }^{3} \mathrm{H}$-cholesterol released from the $\mathrm{OCL}$ into the medium after incubation with acceptors, as described in Materials and Methods. We found efficient ${ }^{3} \mathrm{H}$-labeled cholesterol transfer from OCLs to MBCD (20 mM) and HDL $(400 \mu \mathrm{g} / \mathrm{ml})$ at rates comparable to those for mesenchymal cells (osteoblastic and fibroblastic cells, data not shown). MBCD promoted rapid cholesterol efflux with $80 \%$ transferred from OCL (versus $3 \%$ in controls) within $1 \mathrm{~h},(P<0.001)$. Transfer to $\mathrm{MBCD}$ at $15 \mathrm{mM}$ elicited a similar response. Cholesterol transfer to $\mathrm{HDL}$ and ApoAl was much slower, at 70 and $36 \%$ versus $12 \%$ in controls $(P<0.001)$ in $24 \mathrm{~h}$, respectively. These profound differences in the kinetics of cholesterol efflux have been reported also in other cell systems such as in fibroblasts, in which MBCD was shown to accept cholesterol at up to 70 -fold greater rates $\left(V_{\max }\right)$ than HDL. ${ }^{19}$

\section{Cholesterol removal via MBCD induces OCL apoptosis}

The very low rate of de novo sterol synthesis in OCLs ${ }^{18}$ suggests the possibility that these terminally differentiated cells could depend on external sources to control cellular cholesterol levels. This would be consistent with the epidemiological link between lipoproteins and osteoporosis. To test this hypothesis, we examined the effects of rapid cholesterol removal, via $M B C D$, on OCL life span. OCLs were treated with MBCD (5-20 mM) or left untreated for up to $2 \mathrm{~h}$, after which the media were replaced with media containing lipoproteindeficient FBS (LPDS) to limit cholesterol uptake from the medium. Interestingly, MBCD treatment caused extensive dose- and time-dependent induction of OCL apoptosis, which we assessed microscopically in the large, multinucleated $\mathrm{OCL}$ population (Figure 1). At $5 \mathrm{~h}$ after initial treatment, $\mathrm{OCL}$ contained numerous vacuoles (Figure $2 \mathrm{~b}$ ). Classical apoptotic signs were later observed between 6 and $12 \mathrm{~h}$ of treatment. This included membrane blebbing (Figure 2e), nuclear condensation (Figure 1a,b and $\left.2 \mathrm{e}, \mathrm{e}^{\prime}, \mathrm{f}, \mathrm{f}^{\prime}\right)$, caspase-3 activation (Figure 1e), actin cytoskeleton disruption (Figure 1c,d and 2d) and formation of apoptotic bodies (Figure 2f). We and others have previously found that nuclear condensation/ pyknotic body formation correlates with positive TUNEL staining in this model system ${ }^{20,21}$. The apoptotic response seemed remarkable since mesenchymal and HepG2 cells did not undergo apoptosis in response to similar MBCD treatment (data not shown). Similar $2 \mathrm{~h}$ treatment was previously shown
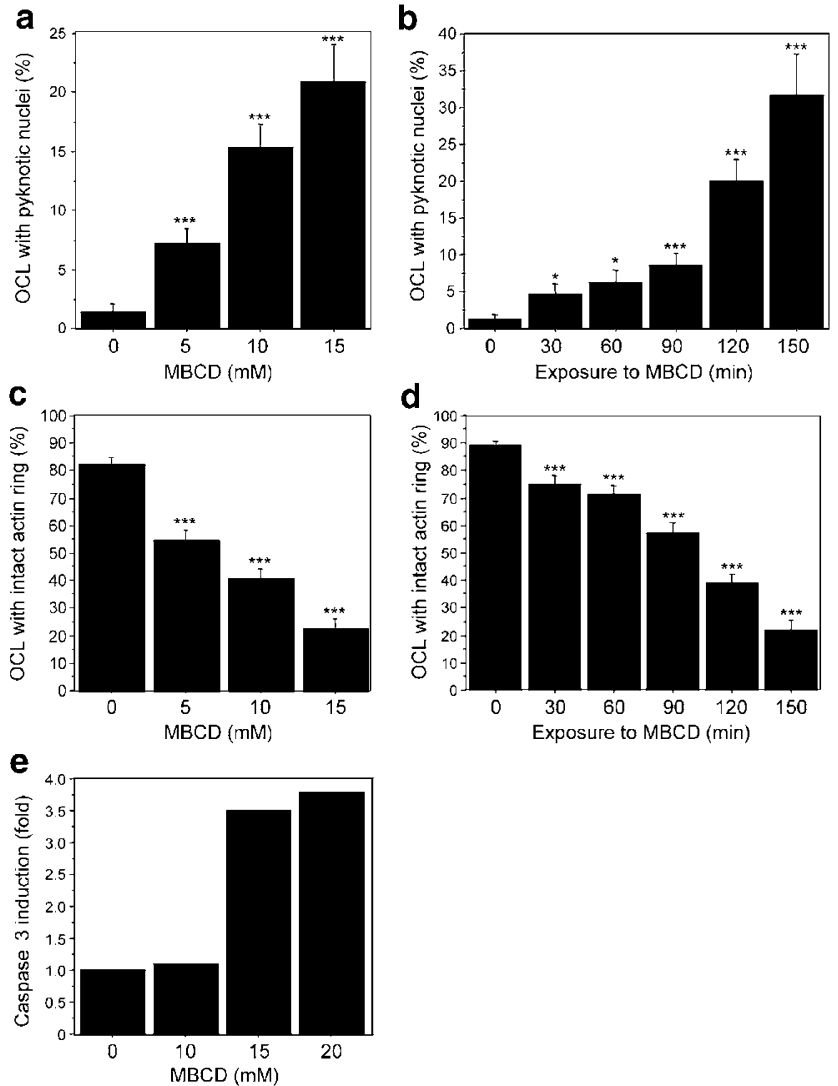

Figure 1 Removal of cholesterol with MBCD induces OCL apoptosis. OCLs were treated with $M B C D$ at several doses and for different times, as noted below. After treatment, cells were further cultivated in medium containing $10 \%$ LPDS to monitor survival. Time- and dose-dependent studies showed maximal induction of apoptosis with equivalent effects at 15 or $20 \mathrm{mM}$, respectively, after a 9-12 h post-treatment period. Data were collected within these ranges based on morphological examination by microscopy. (a,c) TRAP-positive OCLs were examined for (a) nuclear and (c) actin cytoskeleton integrity $12 \mathrm{~h}$ after $90 \mathrm{~min}$ MBCD treatments at indicated concentrations. (b, d) OCLs were treated with $20 \mathrm{mM} M B C D$ for indicated times, after which cultures continued $9 \mathrm{~h}$ in the absence of MBCD. TRAP-positive OCLs were assessed for (b) nuclear and (d) actin cytoskeletal integrity. (e) Dose-dependent effects of MBCD on caspase 3 activity immediately following $2 \mathrm{~h}$ treatments. The bars represent mean \pm S.E. ${ }^{*} P<0.05,{ }^{* \star \star} P<0.001$ (Co versus treatment)

to be nontoxic to fibroblasts, although continuous $8 \mathrm{~h}$ exposure could induce some cell death. ${ }^{19}$ Although there was no evidence of cell death in MB1.8, NIH/3T3 or HepG2 cells, initial and transient morphological rounding was observed (data not shown). This response and the actin disruption seen in OCLs suggest that the cytoskeleton was commonly affected following cholesterol removal. Indeed, disruption of the ring-like f-actin pattern in OCLs (up to $67 \%$ greater than in controls, Figure 1c, d) was more prominent than the induction of nuclear condensation (greater by up to $31 \%$, see Figure $1 \mathrm{a}, \mathrm{b})$ when quantified $12 \mathrm{~h}$ after MBCD treatment.

The earliest response to MBCD measured in the OCL was caspase activation, which was evident at 60 min (data not shown) and maximally increased after 120 min (Figure 1e) of continuous treatment. Morphological apoptosis was not apparent at either initial time point. A similar magnitude of caspase activity was observed $9 \mathrm{~h}$ after MBCD treatment 

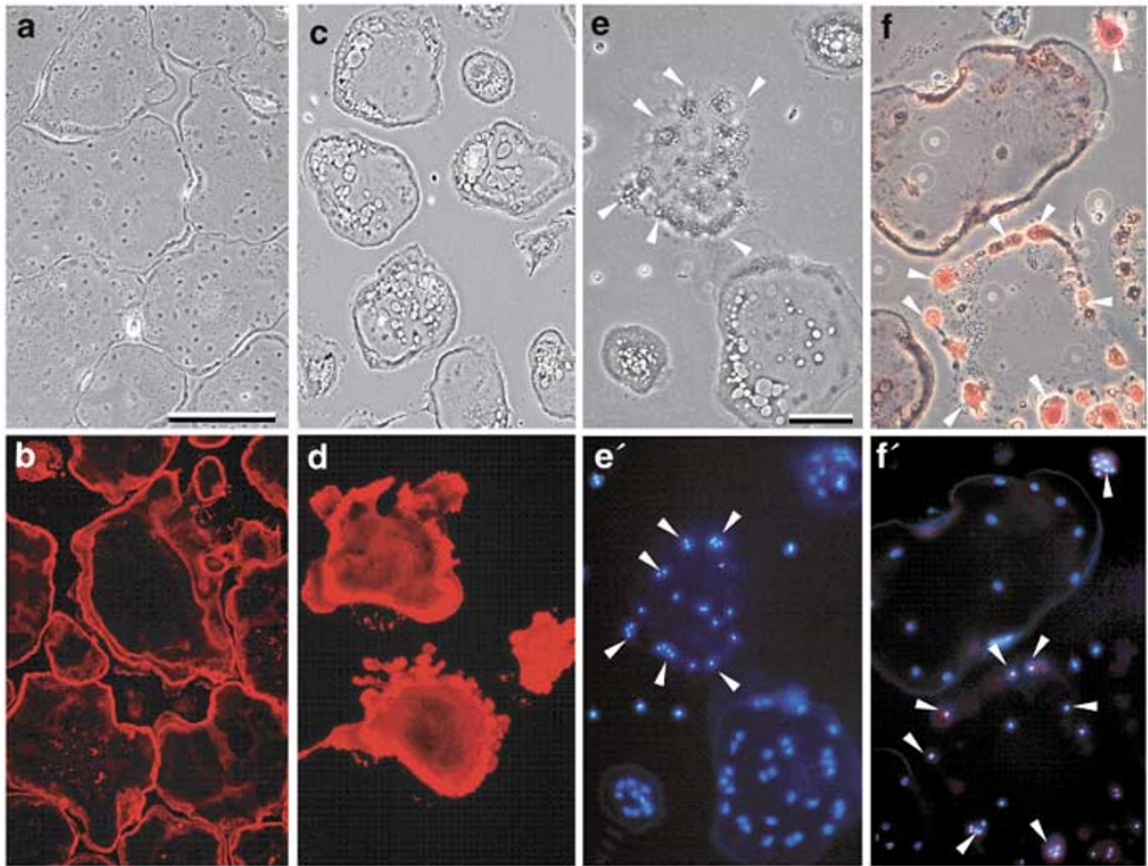

Figure 2 Morphological features of OCL apoptosis after cholesterol removal. Purified OCLs were untreated $(\mathbf{a}, \mathbf{b})$ or treated with $20 \mathrm{mM} \mathrm{MBCD}(1 \mathrm{~h}$ followed by $6 \mathrm{~h}$ ( $\mathbf{c}-$ $\left.\mathbf{e}, \mathbf{e}^{\prime}\right)$ or $9 \mathrm{~h}\left(\mathbf{f}, \mathbf{f}^{\prime}\right)$ without treatment). OCLs were stained for actin cytoskeletal $(\mathbf{b}, \mathbf{d})$ and nuclear $\left(\mathbf{e}^{\prime}, \mathbf{f}^{\prime}\right)$ integrity, as described in Materials and Methods. Morphology (a, $\mathbf{c}$ and actin staining $(\mathbf{b}, \mathbf{d})$ of control $(\mathbf{a}, \mathbf{b})$ versus MBCD-treated OCLs $(\mathbf{c}, \mathbf{d})$. (e) Phase-contrast and $\left(\mathbf{e}^{\prime}\right)$ nuclear integrity of OCL in an early stage of apoptosis. Arrowheads indicate surface blebs containing pyknotic nuclei. (f) TRAP staining and ( $\left.f^{\prime}\right)$ nuclear integrity of OCL in a later stage of apoptosis. TRAP-positive apoptotic bodies are indicated with arrowheads and contain pyknotic nuclei. Scale bars indicate $340 \mu \mathrm{m}(\mathbf{a}-\mathbf{d})$ and $100 \mu \mathrm{m}\left(\mathbf{e}, \mathbf{e}^{\prime}, \mathbf{f}, \mathbf{f}^{\prime}\right)$

(data not shown) at a time point when morphological apoptosis was apparent. However, when FBS was substituted for LPDS in the media used to maintain the OCLs after MBCD treatment, apoptosis was suppressed by one-third at this later time point, as assessed by quantifying multinucleated OCLs with pyknotic nuclei (data not shown). This suggested that although the apoptotic program was immediately activated by MBCD, the response was asynchronous within the OCL population and one-third of the cells that had not already committed to the apoptotic program were rescued by the subsequent restoration of cholesterol levels via the lipoproteins found in normal FBS.

By comparison to osteoblasts, fibroblasts and hepatocytes, OCLs showed high sensitivity to rapid cholesterol removal. Interestingly, other cells of the macrophage/monocyte lineage (J774 and Raw264.7 cells) shared this sensitivity and responded to MBCD treatment by undergoing apoptosis, albeit at a somewhat later time point (data not shown). Whereas OCL apoptosis was seen at 5-10 h, both J774 and Raw264.7 cells appeared normal during this time. However by $24 \mathrm{~h}$, extensive apoptosis was observed. Thus several cell types from the macrophage/monocyte lineage did undergo apoptosis in response to rapid cholesterol removal, the most profound response being seen in OCLs.

\section{HDL induces OCL apoptosis, while LDL extends survival}

To further test the role of external cholesterol on OCL lifespan, we examined the physiologically relevant effects of HDL and LDL particles. HDL-mediated removal of OCL cholesterol
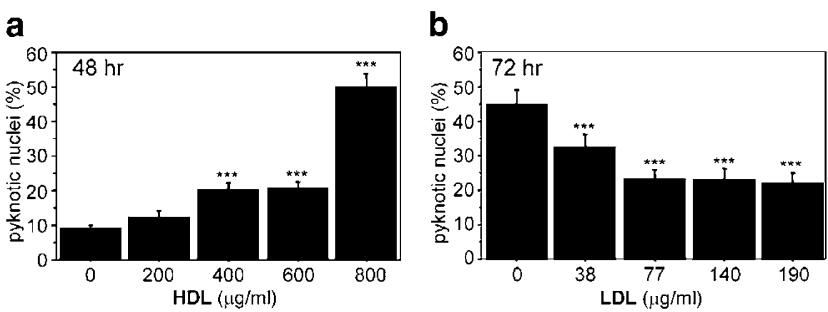

Figure 3 Removal of cholesterol induces $\mathrm{OCL}$ apoptosis, while addition increases survival. $(\mathbf{a}, \mathbf{b})$ Dose-dependent effects of $(\mathbf{a}) \mathrm{HDL}(48 \mathrm{~h})$ or $(\mathbf{b}) \mathrm{LDL}$ $(72 \mathrm{~h})$ on nuclear integrity. After treatments, OCLs were stained for both TRAP and DNA as in Materials and Methods. OCLs with pyknotic nuclei were quantified and are expressed as a percent of the total population. Dose-dependent effects of (a) HDL and (b) LDL ( $n=3$ for both analyses). The bars represent means \pm S.E. ${ }^{* \star *} P<0.001$ (Co versus treatment)

induced dose-dependent apoptosis featuring the same classical apoptotic signs as observed with MBCD treatment (Figure 2), by up to five-fold (Figure 3a). As expected, the timeframe was much longer than that for MBCD (48 versus $1 \mathrm{~h})$, consistent with the slower kinetics of cholesterol removal by HDL. In addition, note that some subclasses of HDL are not full acceptors but are also capable of donating cholesterol. Similarly, cholesterol removal using ApoAl particles lead to a significant, dose-dependent induction of OCL apoptosis by up to $40 \%$ (data not shown). To test if $\mathrm{HDL}$, like MBCD, could induce apoptosis in other cells, we also examined its effects on macrophages, osteoblasts, fibroblasts and hepatocytes. However, unlike the OCL, all cell types remained viable after extended ( $72 \mathrm{~h}$ ) HDL treatment (data not shown). Thus among the cell types tested, HDL-induced apoptosis was limited to 
OCLs, which seem to exhibit the highest sensitivity to cholesterol withdrawal.

Apoptotic death in response to cholesterol removal by HDL suggested that lipoproteins can control OCL lifespan and that the cholesterol donor LDL might extend the lifespan of OCL in vitro. In general, purified OCLs maintained in the presence of $M-C S F$ and RANKL remain mostly intact over a period of $48 \mathrm{~h}$ followed by a steep decline in their survival rate with substantial spontaneous apoptosis seen at $72 \mathrm{~h}$. Consistent with our hypothesis, LDL exposure of OCLs for $72 \mathrm{~h}$ significantly reduced the number of apoptotic OCLs by $50 \%$ (Figure $3 \mathrm{~b}$ ) as measured by quantifying OCL with pyknotic nuclei. Thus, HDL and LDL have the potential to modulate OCL lifespan: the cholesterol acceptor, HDL, induces apoptosis, while the cholesterol donor, LDL, extends lifespan.

\section{Cholesterol removal impairs cytokine survival signaling to Akt, mTOR and S6 kinase}

It was recently shown that cholesterol removal via MBCD could negatively impact RANKL signaling to Akt, although it had no effect on signaling to $\mathrm{NF}-\kappa \mathrm{B}$. ${ }^{22}$ We very recently found that RANKL and M-CSF signaling also activate the $\mathrm{mTOR}$ and S6 kinase (S6K) pathway and that this is critical for OCL survival. ${ }^{23}$ Whereas RANKL signaling to Akt elicits only a small stimulation, signaling to the mTOR/S6K pathway is robust. We therefore examined the impact of MBCD treatment on cytokine-induced activation of several targets in this pathway. As expected, M-CSF profoundly stimulated phosphorylation of Akt (Thr 308) ranging from 7- to 38-fold at $30 \mathrm{~min}$, depending on the experiment (Figure 4a). However, MBCD pretreatment of OCLs for $45 \mathrm{~min}$ reduced signaling to Akt by MCSF and RANKL to $50 \%$. Meanwhile, RANKL stimulation was minimal, as we have previously reported. ${ }^{23}$ In most replicates, RANKL did not stimulate Akt, and there was no response to pretreatment with MBCD (Figure 4a). Akt signaling participates in regulation of S6K activity via TSC2 and $\mathrm{mTOR}$, which regulate activation via phosphorylation of Thr 389 in S6K. ${ }^{25}$ We next measured the phosphorylation of S6K (Thr 389), and its activity on the downstream target, S6 (Figure 4b). M-CSF stimulated phosphorylation of S6K and S6 by 4.2- and 7.6-fold, respectively. As we have previously reported, RANKL, which did not substantially activate Akt, consistently induced S6K and S6 phosphorylation by two- and 4.2-fold, respectively. Interestingly, pretreatment with MBCD strongly suppressed the stimulatory effects of both M-CSF and RANKL on S6K phosphorylation up to $88 \%$, as measured at $30 \mathrm{~min}$, and reduced $\mathrm{S} 6$ phosphorylation by about $60 \%$. In order to examine effects of MBCD treatment on mTOR more closely, we also assessed the phosphorylation of 4E-BP1, a translational regulator that can act as a direct substrate of mTOR. Whereas M-CSF and RANKL stimulated phosphorylation of 4E-BP1 (Ser 65) in control OCLs by up to 9.8- and 3.5-fold (Figure 4b), respectively, pretreatment with MBCD reduced these effects by an average of $70 \%$. In certain replicates, MBCD pretreatment completely abrogated RANKL-induced 4E-BP1 phosphorylation. Together, these data demonstrate that MBCD-mediated removal of cholesterol has a profound impact on survival cytokine-induced

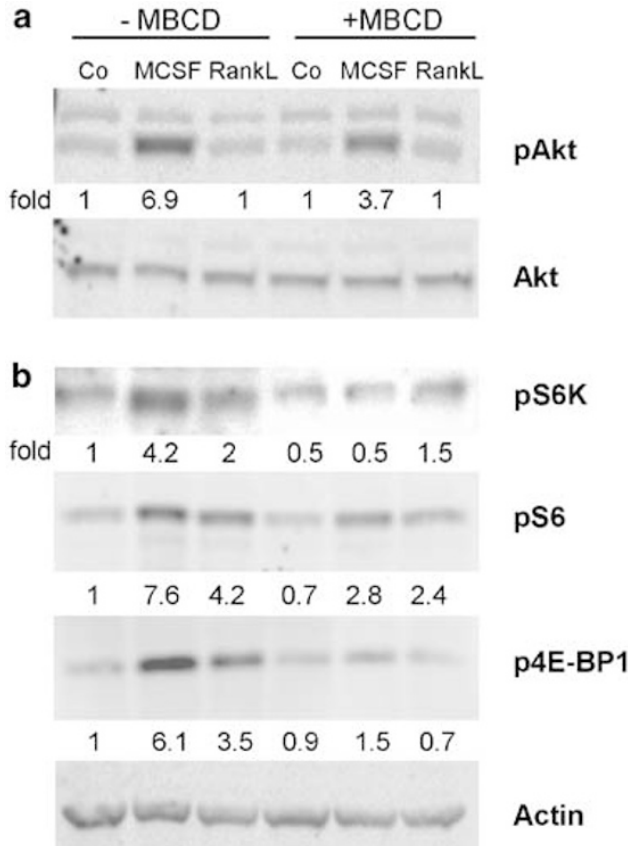

Figure 4 Cholesterol removal impairs cytokine signaling to mTOR and S6 kinase. (a) Purified OCL were pretreated with or without methyl- $\beta$-cyclodextrin (MBCD, $15 \mathrm{mM}$ ) in medium containing $0.5 \%$ FBS for $45 \mathrm{~min}$, and stimulated with M-CSF $(100 \mathrm{ng} / \mathrm{ml})$ or sRANKL $(200 \mathrm{ng} / \mathrm{ml})$ for $30 \mathrm{~min}$, as indicated. Cell lysates were immunoblotted with phosphospecific antibodies for Akt, S6 and 4E-BP1 and S6K1. Blots were stripped and reprobed with control antibodies for Akt and actin. Relative band intensities (versus control) are indicated beneath each lane, and are normalized to Akt (a) or actin (b) expression levels. One representative experiment out of three repeats with similar results is shown

signaling to the Akt and especially the mTOR/S6K pathway. Negative effects on these kinases and their respective substrates are consistent with the capacity of MBCD to induce apoptosis in the OCL.

\section{Cholesterol efflux upregulates hydroxymethylglutaryl coenzyme A reductase (HMGCR) in mesenchymal and liver cells, but not OCLs}

Induction of OCL apoptosis by MBCD suggested the possibility that the normal responses to cholesterol removal (i.e. induction of cholesterol synthesis machinery) might be absent in these cells. To test the degree to which the cholesterol biosynthetic machinery was induced in OCLs by cholesterol removal, we examined feedback induction of HMGCR, a critical enzyme of this pathway. HMGCR mRNA expression is ordinarily induced when cellular cholesterol levels decline, via sterol regulatory elements within its promoter. ${ }^{26,27} \mathrm{MBCD}$, combined with lovastatin, has previously been shown to increase HMGCR mRNA by threefold. ${ }^{28}$ We have previously observed that OCLs synthesize very little sterol ${ }^{18}$ and undergo apoptosis in response to lovastatin treatment. ${ }^{20}$ Lovastatin was therefore omitted in our experiments to avoid confounding effects of apoptosis. Cells were treated with MBCD for $1 \mathrm{~h}$, shown to remove $80 \%$ of 
cellular cholesterol, and then maintained in LPDS for a period of $4 \mathrm{~h}$, which is a time point well before profound apoptosis in OCL can be observed. In osteoblastic, fibroblastic and hepatic cells, HMGCR mRNA expression was, as expected, induced 2-4-fold after treatment with MBCD (Figure 5a). Meanwhile, although OCLs could rapidly and extensively transfer cholesterol to MBCD, no significant HMGCR mRNA induction (1.1fold) was observed (Figure 5a). Furthermore in the uninduced state (i.e. no MBCD treatment), basal levels of HMGCR mRNA expression were comparatively low. This and the lack of response to MBCD treatment indicate absence of feedback regulation of cholesterol synthesis in OCLs, but not in other cell types tested.

We also examined caveolin expression in OCLs in comparison to other cells. Caveolin interacts with cholesterol in caveolae membranes and appears to play a major function in transporting cholesterol between caveolae and the endoplasmic reticulum and Golgi apparatus. The caveolin promoter contains two sterol regulatory elements, which control expression in response to changes in cholesterol levels. ${ }^{29}$ Interestingly, in OCLs as well as J774 and Raw 264.7 cells, all derived from the macrophage/monocyte lineage, caveolin-1 protein was expressed at extremely low levels (Figure 5b). This was in contrast to mesenchymal MB1.8 osteoblasts and NIH3T3 fibroblasts, where a robust caveolin1 signal was detected. Caveolin-2 was abundantly expressed in the $\mathbf{J 7 7 4}$ macrophages, and a faint signal was detected in RAW 264.7 macrophages and in OCLs (Figure 5b). However, it is notable that caveolin-2 lacks the three cysteine palmitoylation motifs found in caveolin-1 that are essential for cholesterol binding and for proper transport of caveolin to the plasma membrane. ${ }^{30}$ Absence of caveolin expression in HepG2 cells (Figure 5b) has been previously described. ${ }^{31}$ For the OCL this suggests that, in addition to a lack of substantial

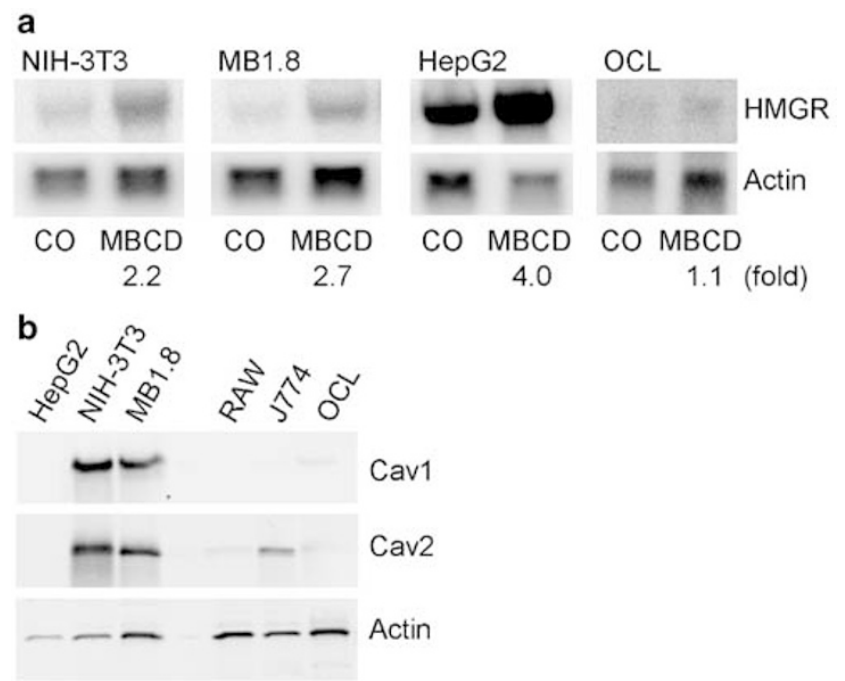

Figure 5 Cholesterol efflux induces feedback regulation of cholesterol synthesis in mesenchymal cells, but not in OCL. Cells have been treated with/ without $15 \mathrm{mM} \mathrm{MBCD}$ for $1 \mathrm{~h}$, thereafter maintained in LPDS for $4 \mathrm{~h}$ followed by RNA extraction. (a) Induction of HMGCR mRNA in untreated and MBCD-treated $\mathrm{NIH} / 3 \mathrm{~T} 3, \mathrm{MB} 1.8$, HepG2 cells and purified OCLs, measured by Northern analysis. (b) Expression of caveolin-1 and -2 protein in untreated HepG2, NIH/ 3T3, MB1.8, Raw 264.7, J774 and OCLs was assessed by Western blot analysis cholesterol synthesis and feedback regulation of HMGCR, these cells may also have limited ability to transport cholesterol intracellularly through caveolin-1. The absence of these internal sterol regulatory mechanisms might explain the apoptotic response of OCLs to cholesterol withdrawal.

\section{OCL formation in the LDL receptor - I- mouse: impaired spreading/fusion and survival}

To extend beyond pharmacological observations described above, we used a genetic approach involving the LDL receptor $-/-$ mouse (hereafter $-/-$ ) to examine $\mathrm{OCL}$ formation and survival. It is notable that both $+/+$ and $-/-$ OCLs were generated using mouse MB1.8 osteoblast-like cells, derived from a $+/+$ background, to drive differentiation in response to $1,25(\mathrm{OH})_{2}$ vitamin $\mathrm{D}_{3}$, as described in Materials and Methods. OCL formation using the bone marrow of $-/-$ versus C57BL6/J background mice (hereafter $+/+$ ) revealed that OCLs from -/- mice were significantly smaller (Figure $6 \mathrm{a}, \mathrm{b})$. This was assessed in OCL $(-/-) /$ osteoblast $(+/+)$ cocultures by staining for the OCL marker enzyme, tartrateresistant acid phosphatase (TRAP). In -/- males, a 5.8-fold reduction in the proportion of large TRAP-positive OCLs ( $>340 \mu \mathrm{m}$ in diameter) was observed, while in females there was a 2.3-fold reduction on day 9 of culture (Figure 6c). There was no enhancement of OCL size between days 7 and 11 of differentiation (data not shown), suggesting that formation of OCL $(>340 \mu \mathrm{m})$ was suppressed rather than delayed. As expected, the reduction in large OCLs in -/- cultures was accompanied by a significant increase in the number of smaller multinucleated TRAP-positive OCLs $(<340 \mu \mathrm{m}$, containing at least five nuclei, arrows in Figure $6 \mathrm{~b}$ ) and a general shift towards smaller sized OCLs (Figure 6d). OCLs from -/cultures mostly fell into the smallest grouping $\left(<10000 \mu \mathrm{m}^{2}\right)$, while within the $+1+$ cultures, most OCLs ranged from $10000-50000 \mu \mathrm{m}^{2}$.

Interestingly, small -/- OCLs contained numerous nuclei and demonstrated irregular morphologies, as visualized by TRAP staining (Figure $6 \mathrm{e}, \mathrm{g}$ ). Phalloidin staining revealed that the f-actin rings in the small -/- OCLs, although often limited to small areas within the cell, frequently spread beyond the limits of TRAP staining (Figure 6f). Nonetheless, the f-actin cytoskeleton was intact and arranged in a ring-like pattern. During the OCL purification process, we noticed that these small, irregular shaped -/- OCLs were less tightly attached to the extracellular matrix. Indeed, while large OCLs were typically resistant to collagenase treatment, most of the small -I- OCLs were detached. We quantified the number of collagenase-sensitive OCLs by transferring them into new culture vessels and counting after reattachment. By this measure, we observed a significant 1.6-fold increase in collagenase-sensitive $-/-$ versus $+/+$ OCLs (data not shown). Interestingly, after replating, the -/- OCLs adopted the more typical round morphology generally seen in $+/+$ OCLs.

We also quantified the mean area of OCLs from female mice. Consistent with the reduction in the number of large OCLs (Figure 6c), the mean size of -/- OCLs was reduced 2.4-fold versus $+/+$ OCLs (Figure 7f). To mimic the effects of 
C57BL6 $(+/+)$
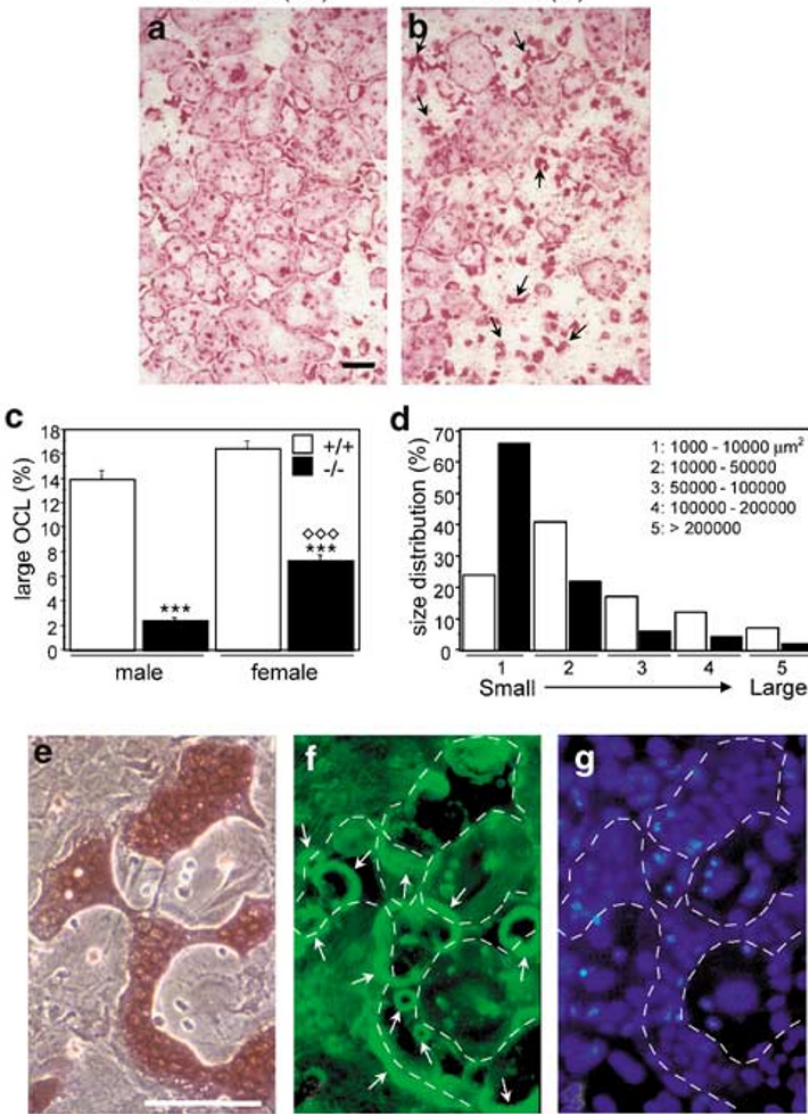

Figure 6 Reduced spreading and/or fusion of LDLR-/- OCLs. OCL formation with bone marrow cells from background (C57BL6J) or LDLR-/- mice. Morphologies of TRAP-stained (a) $+I+$ and (b) $-/-$ OCLs, and (c) percent of large ( $>340 \mu \mathrm{m}$ diameter) male and female OCLs. Arrows in (b) indicate some of the small, multinucleate OCLs. (d) Size distribution of $+I+$ and $-/-$ female OCLs. Size groupings are indicated (inset and beneath $X$-axis). (e) TRAP, (f) actin and $(\mathbf{g})$ nuclear staining of small, multinucleated $-/-$ OCLs. Arrows in (f) indicate the 'actin rings', the white lines in (f) and $(\mathbf{g})$ mark the outlines of TRAPpositive OCLs as seen in panel e. Scale bars represent $340 \mu \mathrm{m}(\mathbf{a}, \mathbf{b})$ and $50 \mu \mathrm{m}$ $(\mathbf{e}-\mathbf{g})$, error bars in (c) represent means \pm S.E. ${ }^{* * *} P<0.001(+1+$ versus -1 $-), \diamond \diamond \diamond P<0.001$ ( $-I-$ male versus $-I-$ female)

LDLR deletion, we also examined OCL formation using LPDScontaining medium. The morphology of TRAP-positive $+/+$ OCLs in the presence of LPDS (Figure 7b) resembled that of $-1-$ OCLs in normal FBS (Figure 7c), showing a four-fold reduction in the number of large OCLs (Figure 7e) and a threefold reduction in the mean OCL size (Figure 7f). Interestingly, the use of LPDS during differentiation further reduced the number of large OCLs in -/- cultures by about two-fold versus that seen with FBS (Figure 7e). Indeed, in LPDS there was no difference in the mean area of $+/+$ and $-/$ - OCLs (Figure 7f). Overall, the findings demonstrate that cholesterol uptake during differentiation via the LDLR has a major influence on OCL morphology, and also suggests that OCLs have other ways than via the LDLR to import extracellular cholesterol. In support with this hypothesis, we incubated the OCLs with a cholesterol-cyclodextrin complex for $30 \mathrm{~min}$ daily. Such cholesterol-saturated complexes have been shown to effectively and rapidly enrich cells with cholesterol, ${ }^{32}$ thereby bypassing the absence of the LDLR. In the
osteoblast-OCL coculture system, pulsatile treatment with cholesterol-cyclodextrin complexes significantly increased the formation of large $-/-$ OCLs $(>340 \mu \mathrm{m})$ up to four-fold (Figure $7 \mathrm{c}-\mathrm{d}, \mathrm{g}$ ). This treatment also had a positive effect on OCL formation in $+/+$ cultures, although the effect was not always statistically significant.

In separate analyses, we examined the survival of $-/-\mathrm{OCL}$ after purification. For these analyses, both $-I-$ and $+I+$ OCL were maintained for 1 and 2 days in FBS supplemented with the differentiation/survival cytokines M-CSF and RANKL. In three of four experiments, the rate of spontaneous apoptosis was significantly increased by greater than $60 \%$ for $-/$ - OCLs versus $+1+$ OCLs. Spontaneous apoptosis was observed after both 24 and $52 \mathrm{~h}$ of culture (Figure $8 \mathrm{a}-\mathrm{c}$ ) and did not require cholesterol removal by MBCD or HDL. These data are consistent with the observation that LDL extends OCL lifespan and that the inability of cholesterol uptake via the LDLR leads to induction of apoptosis, albeit milder than that seen with pharmacological cholesterol removal (Figure 1).

\section{Discussion}

Osteoclasts are terminally differentiated, multinucleated cells formed by the fusion of mononuclear progenitors of the monocyte/macrophage family. OCL activation results in the degradation of the calcified collagenous bone matrix. The delicate balance between bone resorption by OCLs and deposition of new bone by osteoblasts determines bone mass in the adult undergoing consistent adaptive bone remodeling. Disparity of these coupled activities in favor of bone resorption results in the loss of bone and deterioration of its trabecular architecture leading to osteoporosis. Interestingly, osteoporosis often coexists with atherosclerotic calcification in patients, associated with formation of bone mineral in vascular walls and simultaneous calcium loss from bone. ${ }^{1,2,6,7}$ Growing evidence suggests that abnormalities in lipid metabolism could be a common factor underlying both diseases, ${ }^{10,16,33-35}$ and that plasma lipids might play a role in maintaining bone mass. ${ }^{13,36-38} \mathrm{~A}$ better understanding of the coupling of osteoporosis and atherosclerosis is of critical importance as indicated by some studies whereby treatment of one disease may have beneficial effects on the other. ${ }^{39-44}$

In the present study, we investigated the effects of exogenous cholesterol on OCL formation and survival. We show here for the first time that lipoproteins influence survival of purified OCL, and that the addition of cholesterol via native LDL could double the lifespan of purified OCL in vitro. More importantly, failure to gather cholesterol seems to have a negative impact on OCL survival, since purified LDLR-/OCLs showed significantly higher levels of apoptosis than + I + OCLs. Conversely cholesterol deficiency, caused by the use of LPDS in the coculture system, significantly suppressed the formation of TRAP-positive, multinucleated OCLs. This is in concordance with earlier reports suggesting a role for LDL, isoPGE2 and oxidized LDL in OCL fusion and differentiation via effects on bone marrow hematopoietic precursors. ${ }^{17,45}$

Furthermore, we find that cholesterol withdrawal has detrimental effects on OCL survival. The correlation between 

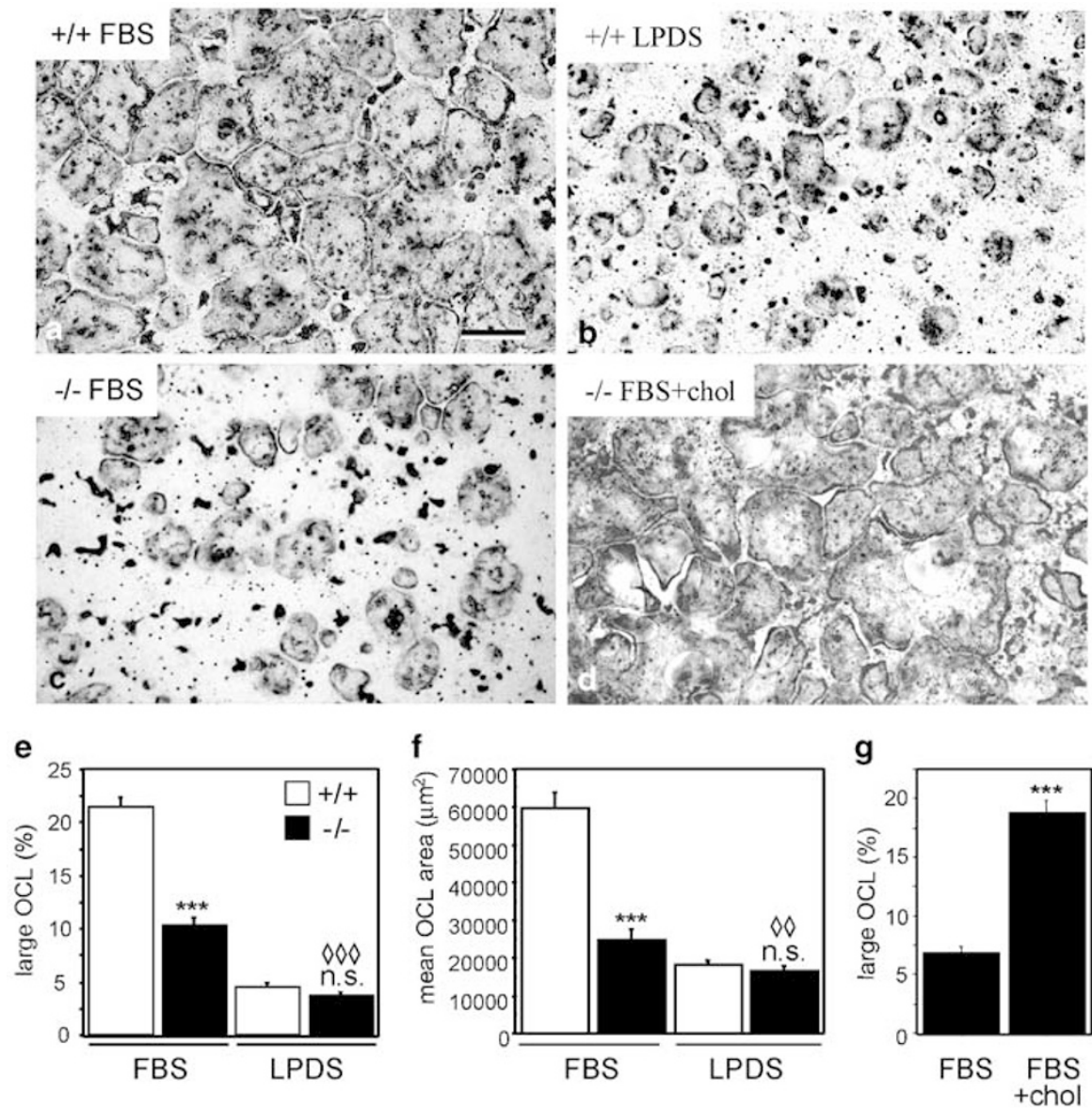

Figure 7 Effects of cholesterol withdrawal and repletion on OCL formation. (a-d) TRAP staining of OCLs from $(\mathbf{a}, \mathbf{b})+/+$ and $(\mathbf{c}, \mathbf{d})-/-$ mice. $+/+$ OCLs were formed in the presence of (a) FBS or (b) LPDS, while -I- OCLs were formed in the presence of (c) FBS or (d) FBS with daily pulsatile cholesterol treatments (MBCDcholesterol inclusion complexes), as described in Materials and Methods. (e) Percent of large (>340 $\mu \mathrm{m}$ diameter) and (f) mean area of $+I+$ and $-/-$ OCLs differentiated in FBS versus LPDS-containing medium. (g) Change in large $-/-$ OCLs when formed in the absence (FBS) or presence (FBS + chol) of MBCDcholesterol inclusion complexes. Scale bar represents $340 \mu \mathrm{m}$ (a-d); error bars in (e-f) represent means \pm S.E. ${ }^{* \star *} P<0.001(+I+$ versus $-I-)$, $\diamond \diamond \diamond P<0.001$, $\diamond \diamond P<0.01$ ( - I- FBS versus -I- LPDS); (g) ${ }^{\star * *} P<0.001$ ( - - FBS versus - / FBS plus MBCD-cholesterol inclusions)
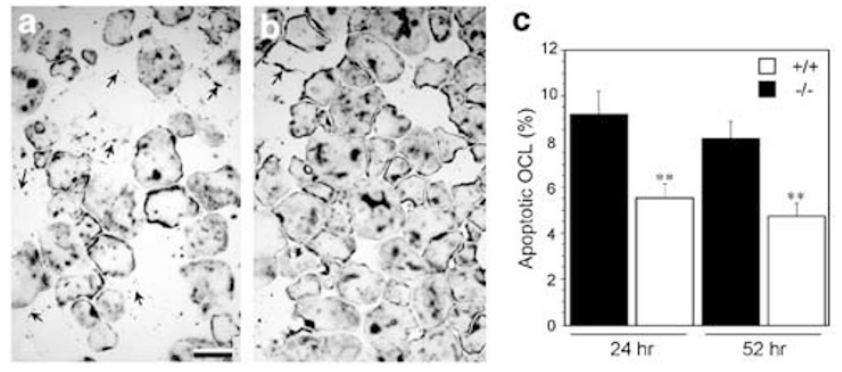

Figure 8 Reduced survival of LDLR-I-OCLs. OCLs derived from $+/+$ and $-I-$ mice were purified and maintained for 1-2 days in the presence of M-CSF $(15 \mathrm{ng} / \mathrm{ml})$ and SRANKL $(25 \mathrm{ng} / \mathrm{ml})$. Nonapoptotic and apoptotic OCLs were quantified as TRAP-positive, intact cells or a ring of apoptotic bodies (arrows), respectively, as described in Figure 3. (a) $-1-$ and (b) $+1+$ OCLs $52 \mathrm{~h}$ after purification. (c) Percentage of apoptotic OCLs 24 and $52 \mathrm{~h}$ after purification. Scale bar represents $340 \mu \mathrm{m}(\mathbf{a}, \mathbf{b})$, error bars (c) represent means \pm S.E. ${ }^{\star *} P<0.01(+I+$ versus $-I-)$

cholesterol efflux and OCL apoptosis is reflected by the differences in kinetics of cholesterol removal, which substantially vary for the pharmacological agent $M B C D$, and the physiological cholesterol acceptors HDL and ApoAI. These differences in cholesterol efflux (MBCD $>>\mathrm{HDL}>\mathrm{ApoAl})$ are consistent with reports in other cell systems. ${ }^{19}$ Although the rate of cholesterol release to phospholipid-containing acceptors like HDL can be cell type dependent, ${ }^{46}$ we observed comparable cholesterol efflux rates to HDL in OCLs as well as MB1.8 osteoblasts and NIH3T3 fibroblasts over $24 \mathrm{~h}$ (five-, versus seven-fold, respectively). As a consequence of promoting cholesterol efflux in OCLs, apoptosis was induced up to five-fold, as verified by cell morphology, disruption of the actin cytoskeleton, nuclear condensation and caspase-3 activation. Two cell lines of the macrophage/monocyte lineage (J774, Raw264.7) did also show an apoptotic response to MBCD, but interestingly, among the cell types tested, HDLinduced apoptosis was strictly limited to OCLs. Thus, in our hands the OCL was outstanding in its susceptibility to apoptosis due to cholesterol removal.

It is notable that we have found no previous study showing that native HDL could induce cell death in any cell type. On the contrary, several reports show that HDL protects endothelial cells by blocking the mitochondrial pathway of apoptosis, thereby preventing caspase- 9 and -3 activation, and apoptotic alterations of the plasma membrane. ${ }^{47-49}$ However, glucose 
modification and/or oxidation of HDL resulted in deterioration of the mitochondrial function and apoptosis of endothelial cells. ${ }^{50}$ In the present study, no such prior modification of HDL was necessary to induce OCL apoptosis.

To further investigate the role of cholesterol uptake in $\mathrm{OCL}$ formation and survival, we used the LDLR knockout mouse $(-/-)$ as a model. ${ }^{51}$ These mice are extensively used to investigate lipoprotein metabolism and atherosclerosis. Preliminarily data indicate that the LDLR-/- mice exhibit a bone phenotype with $8 \%$ lower BMD when placed on a high fat diet. ${ }^{52}$ Based on earlier work, ${ }^{16,36}$ it was hypothesized that the observed changes in BMD were due to accumulation of oxidized lipids in bone leading to an inhibition of osteoblastic differentiation. However, additional evidence suggests that lipid oxidation products and hyperlipidemia might also enhance osteoclastic potential and function, ${ }^{45}$ thus making the OCL likely to contribute to the lower BMD. We found that multinucleated -/-OCLs were significantly smaller and more susceptible to spontaneous induction of apoptosis when compared to $+1+$ OCLs. There was a significant 2.3-fold and 5.8-fold difference in the average OCL area between -/and $+/+$ female and male mice, respectively. These apparent gender-based differences were consistently observed in independent experiments. However, the reduction of OCL area in -/- was accompanied by a significant increase in the total number of multinucleated OCL (data not shown). Specifically, there were more multinucleated OCLs, and a greater proportion of these multinucleated OCLs were of a smaller measured size. This indicates that spreading and, perhaps to a lesser extent, fusion of these cells might be impaired. In addition, $\mathrm{OCL}$ formation and size in both LDLR $+/+$ and $-/$ - cultures were equally suppressed when LPDS was used during differentiation, providing further evidence that reduced receptor-mediated cholesterol uptake is a primary driver for the phenotype observed. Interestingly, by limiting exogenous sources of cholesterol (LPDS versus FBS), formation of large OCL (>340 um diameter) was further diminished two-fold in LDLR-/- mice. This suggests that, yet insufficient, OCL have means of cholesterol uptake other than via LDLR.

More importantly, we provide proof for the role of exogenous cholesterol during the OCL formation process by using cholesterol-cyclodextrin inclusion complexes. $\beta$-Cyclodextrin form stable inclusion complexes with cholesterol by incorporating it into their hydrophobic cavity, ${ }^{53-55}$ and (receptor independently) enrich cells with cholesterol. ${ }^{32,56-58}$ Indeed, intermittent incubation of -/-OCLs with cholesterol-cyclodextrin inclusion complexes significantly enhanced the formation of OCLs ( $>340 \mathrm{um}$ ) by $2-4$-fold. This observation verified that the morphological phenotype of LDLR -/- OCL was driven by the loss of functional LDLR and could be rescued by providing cholesterol in a receptor-independent mechanism.

Our experiments do raise the question of why in particular the OCL is so sensitive to cholesterol efflux in comparison to the other cells that we examined. We tested the expression and regulation of HMGCR as a major, rate-limiting enzyme in the cholesterol biosynthetic pathway. Treatments that stimulate cholesterol efflux have been shown to increase the expression of this enzyme at the level of mRNA and protein in various cell types. ${ }^{28,59-62}$ Surprisingly, we found that HMGCR mRNA level was not responsive to MBCD treatment in $\mathrm{OCL}$, although 2-4-fold induction was seen in cell types resistant to MBCD-induced apoptosis (MB1.8, NIH/3T3 and HepG2 cells). Moreover, baseline HMGCR mRNA expression was found to be low in OCLs. Indeed, we previously found a very low level of cholesterol synthesis in OCL as $<0.1 \%$ of radiolabeled mevalonate is incorporated into nonsaponifiable lipids (sterols). ${ }^{18}$ Based on these two observations and the fact that HMGCR is only one of several cholesterol biosynthetic genes regulated via sterol response elements in their promoters, this suggests that more than one enzyme of this biosynthetic pathway is downregulated. Even more so, we describe here extremely low, if any, expression of caveolins (caveolin 1 and -2) in the OCLs. Absence of caveolin-1 in OCLs has been reported very recently in another study. ${ }^{21}$ Caveolins, which form a family of membrane-anchored proteins, have been implied to function in cellular cholesterol homeostasis, particularly intracellular transport of cholesterol. ${ }^{63}$ Altogether our data point towards an impaired feedback regulation of cholesterol synthesis and - transport in these terminally differentiated cells.

OCL survival primarily depends not only on antiapoptotic signaling mediated by M-CSF but also other cytokines like RANKL and TNF $\alpha .{ }^{64,65}$ A very recent study demonstrated that MBCD treatment reduced survival and activity of in vitro generated OCL. ${ }^{21}$ This correlated with impairment of RANKLinduced signaling. In the present study, we observed a partial reduction of M-CSF signaling to antiapoptotic Akt, as well as more substantial inhibition of signaling farther downstream of M-CSF and RANKL to the mTOR/S6K pathway, by cholesterol withdrawal. Signaling to this pathway was greatly reduced (up to $80 \%$ ), especially as related to mTOR activation of S6K and phosphorylation of 4E-BP1. We have previously shown that the mTOR inhibitor, rapamycin, induces OCL apoptosis and suppresses OCL formation. ${ }^{22}$ Thus, the suppressive effects of cholesterol withdrawal on Akt/mTOR/S6K signaling might provide a contributing mechanism by which OCL survival and formation are reduced.

In summary, our data suggest that OCL formation and survival is highly dependent on exogenous sources of cholesterol. Addition of native LDL cholesterol increases OCL viability by suppressing spontaneous apoptosis, while cholesterol removal strongly induces apoptosis in OCL and, to a lesser degree, macrophages. This was accompanied by a profound inhibition on the cytokine-induced signaling to Akt/mTOR/S6K survival pathways. We further suggest that the susceptibility of OCLs to cholesterol removal might be due to impaired feedback regulation of cholesterol synthesis involving HMGCR. OCL from the hyperlipidemic LDLR-/- mouse showed reduced size and lifespan in vitro, indicating a major role for cholesterol delivery via the LDLR in OCL formation and survival. The present findings suggest a regulatory role of lipoproteins in $\mathrm{OCL}$ biology, which might play a role in the epidemiological link between osteoporosis and atherosclerosis.

\section{Materials and Methods}

\section{Cell culture}

Osteoclast-like cells $(\mathrm{OCL})$ were generated in six-well plates by coculturing mouse bone marrow cells with mouse MB1. 8 cells $^{66}$ in differentiation 
medium (MEM- $\alpha$ supplemented with $10 \%$ FBS and $10 \mathrm{nM} 1,25(\mathrm{OH})_{2^{-}}$ Vitamin $\mathrm{D}_{3}$ ) in a humidified atmosphere with $10 \% \mathrm{CO}_{2}$. MB1.8 cells were removed by collagenase treatment, ${ }^{67}$ and purified $\mathrm{OCL}$ were further cultured in the presence of $15 \mathrm{ng} / \mathrm{ml}$ M-CSF (R\&D, Minneapolis, MN, USA) and $25 \mathrm{ng} / \mathrm{ml}$ soluble RANK ligand (sRANKL) (R\&D) in lipoproteindeficient medium containing $92 \%$ less total cholesterol than FBS (MEM- $\alpha$

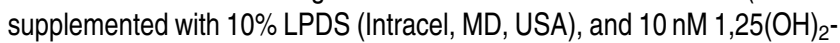
Vitamin $D_{3}$. For signal transduction experiments, purified $\mathrm{OCL}$ were cultured in $0.5 \%$ FBS without cytokines with/without treatment for 1-2 h. $\mathrm{NIH} / 3 \mathrm{~T} 3$ fibroblasts, $\mathbf{J} 774$ macrophages, Raw 264.7 macrophages and HepG2 hepatocytes were purchased from ATCC.

For modulating cholesterol levels in OCL, the following reagents were used at indicated concentrations: LDL (38-190 $\mu \mathrm{g} / \mathrm{ml}$; Calbiochem, San Diego, CA, USA), HDL (200-800 $\mu \mathrm{g} / \mathrm{ml}$; Calbiochem), ApoA1 (20-40 $\mu \mathrm{g} /$ $\mathrm{ml})$, (MBCD (5-20 mM: Sigma, St. Louis, MO, USA).

\section{Preparation of Steroid-MBCD inclusion complexes}

A stock solution of $0.4 \mathrm{mg} / \mathrm{ml}$ cholesterol and $10 \%$ cyclodextrin was prepared by combining $10 \mathrm{ml}$ of $10 \%$ cyclodextrin with $200 \mu$ l of cholesterol $(20 \mathrm{mg} / \mathrm{ml}$ in $2: 1$ methanol/chloroform) at $40^{\circ} \mathrm{C}$ by vortexing. Each solution was freezedried for storage, and filtered through a $0.2 \mu \mathrm{m}$ filter before use. Complexes were added to the cultures for $30 \mathrm{~min}$ at $37^{\circ} \mathrm{C}$ each day, starting with day 5 when first signs of OCL fusion were apparent and until differentiation was complete. After each treatment, media were aspirated, cultures were washed with PBS and regular differentiation medium was added.

\section{Histochemistry}

Osteoclast-like cells were washed with PBS, fixed in 3.7\% formaldehyde for $15 \mathrm{~min}$ and stained as previously described. ${ }^{68}$ Briefly, cells were stained for TRAP in $50 \mathrm{mM}$ sodium acetate $(\mathrm{pH} 5.0), 30 \mathrm{mM}$ sodium tartrate, $0.1 \%$ Triton $X-100$ with $0.3 \mathrm{mg} / \mathrm{ml}$ fast red violet $\mathrm{LB}$ and $0.1 \mathrm{mg} / \mathrm{ml}$ naphthol AS-MX phosphate (both from Sigma). Actin and nuclei were stained with $5 \mathrm{U} / \mathrm{ml}$ TRITC or FITC-labeled phalloidin together with $50 \mu \mathrm{g} /$ $\mathrm{ml}$ Hoechst 33342 dye (both from Molecular Probes, Eugene, OR, USA) and mounted using antifade (Molecular Probes).

\section{OCL survival and actin structure}

OCL were triple-stained as described above. Total OCL and OCL with pyknotic nuclei and/or a disrupted actin cytoskeleton were counted. Each treatment was performed in triplicate wells and at least 35 representative observation fields were assessed per well under $10 \times$ magnification. Data were analyzed by analysis of variance (ANOVA).

\section{Caspase-3 activity assay}

Fluorescent caspase-3 activity assay kit was from Biovision Inc. (Mountain View, CA, USA). Cells were washed with Hank's buffered salt solution (HBSS), and lysed and scraped in the lysis buffer supplied by the manufacturer. Lysates were cleared by centrifugation and supernatants were assayed according to instructions provided with the kit. In all, 20$40 \mu \mathrm{g}$ of total protein was used per assay, and activities were determined after $2 \mathrm{~h}$ incubation at $37^{\circ} \mathrm{C}$. Values are in relative fluorescence units (RFUs) per $\mu \mathrm{g}$ protein.

\section{Cholesterol efflux assay}

MB1.8, NIH-3T3 and purified OCLs in six-well plates were incubated with growth medium containing $10 \%$ LPDS and $1 \mu \mathrm{Ci} / \mathrm{ml}$ of cholesterol $(50 \mathrm{Ci} /$ mmol) (Perkin-Elmer; Boston, MA, USA) for $24 \mathrm{~h}$. Following labeling, cells were washed and incubated for an additional $6 \mathrm{~h}$ in fresh growth medium to allow for equilibration of ${ }^{3} \mathrm{H}$-cholesterol with intracellular cholesterol. Owing to the short lifespan of purified OCLs in culture, the equilibration step was shortened to $6 \mathrm{~h}$ for these and all comparator cell lines. In two control experiments using $\mathrm{NIH} / 3 \mathrm{~T} 3$ fibroblasts, we found that the shorter equilibration period resulted in increased efflux to HDL by $10-25 \%$ after $24 \mathrm{~h}$, while efflux to MBCD $(1 \mathrm{~h}$ ) was slightly increased up to $7 \%$ (data not shown). Efflux was assessed with three different cholesterol acceptors ApoAl, HDL and MBCD. After the efflux period of $1-24 \mathrm{~h}$, media were collected and cells were dissolved in $0.1 \mathrm{M} \mathrm{NaOH}$. Aliquots of both the supernatants and dissolved cells were subjected to liquid scintillation spectrometry. Cholesterol efflux is expressed as the amount of ${ }^{3} \mathrm{H}$ cholesterol in the medium as a percentage of the total label in both fractions.

\section{Preparation of protein lysates and Western blotting}

After treatments, cells were placed on ice and washed twice with ice-cold $\beta$-glycerophosphate-HEPES-buffered solution ( $\beta$-HBS): $50 \mathrm{mM}$ HEPES (pH 7.6),. $\beta$-glycerophosphate (50 mM), EGTA (1 mM), NaCl $(150 \mathrm{mM})$, and then lysed in $\beta$-HBS containing Triton X-100 (0.2\%), microcystin LR $(1 \mu \mathrm{M}), \quad \mathrm{Na}_{3} \mathrm{VO}_{4}(1 \mathrm{mM})$, dithiothreitol $(1 \mathrm{mM})$, phenylmethylsulfonyl fluoride $(1 \mathrm{mM})$ and a protease inhibitor mixture (Sigma) as described. ${ }^{69}$ Protein concentrations were determined using a Bradford reagent kit (BioRad, Hercules, CA, USA).

Equal amounts of protein lysates were loaded and separated on $12 \%$ or 4-15\% gradient Tris- $\mathrm{HCl}$ gels (Bio-Rad). Proteins were transferred onto PVDF membranes, which were blocked with $5 \%$ nonfat milk/5\% BSA in TBST (10 mM Tris- $\mathrm{HCl} \mathrm{pH} \mathrm{8.0,150} \mathrm{mM} \mathrm{NaCl,} \mathrm{0.1 \% Tween-20).} \mathrm{Primary}$ antibodies were incubated overnight at $4{ }^{\circ} \mathrm{C}$ with gentle agitation. Anticaveolin-caveolin-1 and -2 antibody (BD Transduction Laboratories, San Diego, CA, USA), anti-phospho-p70 S6 Kinase (Thr389) antibody, phospho-S6 ribosomal protein (Ser235/236) antibody, phospho-4E-BP1 (Ser65) antibody, phospho-Akt (Thr 308) antibody (all from Cell Signaling Technology, Beverly, MA, USA) were diluted 1:1000-5000 in blocking solution. Detection was performed with alkaline phosphatase coupled secondary antibodies $(1: 10000$, Santa Cruz) and ECF-substrate (Amersham, Piscataway, NJ, USA) using a Storm 860 system (Molecular Dynamics, Sunnyvale, CA, USA).

\section{RNA extraction and Northern blotting}

Total RNA was isolated with Trizol (Invitrogen), electrophoresed, and probed as described previously. ${ }^{24}$ As hybridization probes, we used a pHRed102 Hind-III restriction fragment encoding human HMG CoAreductase (ATCC 57042). To ensure even loading, we hybridized the same blot with a $\beta$-actin CDNA fragment which was amplified by RT-PCR with $\beta$-actin specific primer (Clontech) from human $\mathrm{HL}-60 \mathrm{mRNA}$ (Clontech). Northern blots were exposed and quantitated using a Molecular Dynamics Storm 860 system (Sunnyvale, CA, USA), normalized to $\beta$-actin and expressed as fold induction compared to control.

\section{OCL formation in a hyperlipidemic mouse model: the LDLR-I- mouse}

Six-week-old homozygous LDLR-null (LDLR-/-) mice and background strain C57BL6/J mice were obtained from the Jackson Laboratory (Bar Harbor, ME, USA). OCL formation was performed as described above. In 
some experiments, a lipoprotein-deficient serum was used to replace FBS during OCL differentiation (10\% LPDS instead of $10 \% \mathrm{FBS}$ ), as stated in figure legends. After 7-11 days, cocultures were fixed in $3.5 \%$ paraformaldehyde and triple-stained as described above. The percentage of large OCL ( $>340 \mu \mathrm{m}$ in diameter) was determined by counting the total number of OCL that contain at least five nuclei in at least 40 observation fields per well under $10 \times$ magnification. Analyses were performed in triplicate, yielding at least 120 samples per group. In one set of experiments, the OCL area was quantified for 350 individual OCLs per group using the BioQuant IV image analysis system (BioQuant, Nashville, TN, USA), as noted in legends.

\section{Acknowledgements}

We are grateful to Lorraine Lipfert, Chih-Tai Leu, Patricia Masarachia, Brenda Pennypacker and Don Kimmel for their helpful discussion of this work and technical support.

\section{References}

1. Browner WS, Pressman AR, Nevitt MC, Cauley JA and Cummings SR (1993) Association between low bone density and stroke in elderly women. The study of osteoporotic fractures. Stroke 24: 940-946

2. Von der Recke P, Hansen MA and Hassager C (1999) The association between low bone mass at the menopause and cardiovascular mortality. Am. J. Med. 106: 273-278

3. Kado DM, Browner WS, Blackwell T, Gore R and Cummings SR (2000) Rate of bone loss is associated with mortality in older women: a prospective study. J. Bone Miner. Res. 15: 1974-1980

4. Boukhris R and Becker KL (1972) Calcification of the aorta and osteoporosis. A roentgenographic study. JAMA. 219: 1307-1311

5. Frye MA, Melton Lj, Bryant SC, Fitzpatrick LA, Wahner HW, Schwartz RS and Riggs BL (1992) Osteoporosis and calcification of the aorta. Bone Miner. 19: 185-194

6. Vogt MT, San Valentin R, Rorrest KY, Nevitt MC and Cauley JA (1997) Bone mineral density and aortic calcification: the study of osteoporotic fractures. J. Am. Geriatr. Soc. 45: 140-145

7. Barengolts El, Berman M, Kukreja SC, Kouznetsova T, Lin C and Chomka EV (1998) Osteoporosis and coronary atherosclerosis in asymptomatic postmenopausal women. Calcif. Tissue Int. 62: 209-213

8. Broulik PD and Kapitola J (1993) Interrelations between body weight, cigarette smoking and spine mineral density in osteoporotic Czech women. Endocr. Regul. 27: $57-60$

9. Uyama O, Yoshimoto $Y$, Uamamoto $Y$ and Kawai A (1997) Bone change and carotid atherosclerosis in postmenopausal women. Stroke 28: 1730-1732

10. Yamaguchi T, Sugimoto $T$, Yano S, Yamauchi M, Sow H, Chen $Q$ and Chihara $\mathrm{K}$ (2002) Plasma lipids and osteoporosis in postmenopausal women. Endocrine J. 49: 211-217

11. Steinberg D, Carew TE, Fielding C, Fogelman AM, Mahley RW, Sniderman AD and Zilversmit DB (1989) Lipoproteins and the pathogenesis of atherosclerosis. Circulation 80: 719-723

12. Witztum JL and Steinberg D (1991) Role of oxidized low density lipoprotein in atherogenesis. J. Clin. Invest. 88: 1785-1792

13. Parhami F, Jackson SM, Tintut Y, Le V, Balucan JP, Territo M and Demer LL (1999) Atherogenic diet and minimally oxidized low density lipoprotein inhibit osteogenic and promote adipogenic differentiation of marrow stromal cells. J. Bone Miner. Res. 14: 2067-2078

14. Diascro Jr DD, Vogel RL, Johnson TE, Witherup KM, Pitzenberger SM, Rutledge SJ, Prescott DJ, Rodan GA and Schmidt A (1998) High fatty acid content in rabbit serum is responsible for the differentiation of osteoblasts into adipocyte-like cells. J Bone Miner. Res. 13: 96-106

15. Parhami F and Demer LL (1997) Arterial calcification in face of osteoporosis in ageing: can we blame oxidized lipids? Curr. Opin. Lipidol. 8: 312-314
16. Parhami F, Tintut $Y$, Beamer WG, Gharavi N, Goodman W and Demer LL (2001) Atherogenic high-fat diet reduces bone mineralization in mice. J. Bone Miner. Res. 16: 182-188

17. Sato T, Morita I and Murota S (1998) Involvement of cholesterol in osteoclastlike cell formation via cellular fusion. Bone 23: 135-140

18. Bergstrom JD, Bostedor RG, Masarachia PJ, Reszka AA and Rodan G (2000) Alendronate is a specific, nanomolar inhibitor of farnesyl diphosphate synthase. Arch. Biochem. Biophys. 373: 231-241

19. Kilsdonk EP, Yancey PG, Stoudt GW, Bangerter FW, Johnson WJ, Phillips MC and Rothblat GH (1995) Cellular cholesterol efflux mediated by cyclodextrins. J. Biol. Chem. 270: 17250-17256

20. Reszka AA, Halasy-Nagy JM, Masarachia PJ and Rodan GA (1999) Bisphosphonates act directly on the osteoclast to induce caspase cleavage of mst1 kinase during apoptosis. A link between inhibition of the mevalonate pathway and regulation of an apoptosis-promoting kinase. J. Biol. Chem. 274: 34967-34973

21. Ito M, Amizuka N, Nakajami T and Ozana $H$ (2001) Bisphosphonate acts on osteoclasts independent of ruffled borders in osteosclerotic (ocloc) mice. Bone 28: 609-616

22. Ha H, Kwak HB, Lee SK, Na DS, Rudd CE, Lee ZH and Kim HH (2003) Membrane rafts play a crucial role in receptor activator of nuclear factor kappaB signaling and osteoclast function. J. Biol. Chem. 278: 18573-18580

23. Glantschnig H, Fisher JE, Wesolowski G, Rodan GA and Reszka AA (2003) MCSF, TNF $\alpha$ and RANK-ligand promote osteoclast survival by signaling through mTOR/S6 kinase. Cell Death Diff. 10: 1165-1177

24. Glantschnig H, Varga F and Klaushofer K (1996) The cellular protooncogenes $c$-fos and egr-1 are regulated by prostacyclin in rodent osteoblasts and fibroblasts. Endocrinology 137: 4536-4541

25. Inoki K, Li Y, Zhu T, Wu J and Guan KL (2002) TSC2 is phosphorylated and inhibited by Akt and suppresses mTOR signalling. Nat. Cell Biol. 4: 648-657

26. Fogelman AM, Seager J, Edwards PA and Popjak G (1977) Mechanism of induction of 3-hydroxy-3-methylglutaryl coenzyme $A$ reductase in human leukocytes. J. Biol. Chem. 252: 644-651

27. Osborne TF, Gil G, Goldstein JL and Brown MS (1988) Operator constitutive mutation of 3-hydroxy-3-methylglutaryl coenzyme A reductase promoter abolishes protein binding to sterol regulatory element. J. Biol. Chem. 263: 3380-3387

28. Field FJ, Shreves T, Fujiwara D, Murthy S, Albright E and Mathur SN (1991) Regulation of gene expression and synthesis and degradation of 3-hydroxy-3methylglutaryl coenzyme A reductase by micellar cholesterolin $\mathrm{CaCo-2}$ cells. J. Lipid Res. 32: 1811-1821

29. Bist A, Fielding PE and Fielding CJ (1997) Two sterol regulatory element-like sequences mediate up-regulation of caveolin gene transcription in response to low density lipoprotein free cholesterol. Proc. Natl. Acad. Sci. USA 94: 10693-10698

30. Uittenbogaard A and Smart EJ (2000) Palmitoylation of caveolin-1 is required for cholesterol binding, chaperone complex formation, and rapid transport of cholesterol to caveolae. J. Biol. Chem. 275: 25595-25599

31. Fujimoto $T$, Kogo $H$, Nomura $R$ and Une $T$ (2000) Isoforms of caveolin-1 and caveolar structure. J. Cell Sci. 113 (Part 19) 3509-3517

32. Christian AE, Haynes MP, Phillips MC and Rothblat GH (1997) Use of cyclodextrins for manipulating cellular cholesterol content. J. Lipid Res. 38: 2264-2272

33. Parhami F, Garfinkel A and Demer LL (2000) Role of lipids in osteoporosis. Arterioscler. Thromb. Vasc. Biol. 20: 2346-2348

34. Demer LL (2002) Vascular calcification and osteoporosis: inflammatory responses to oxidized lipids. Int. J. Epidemiol. 31: 737-741

35. Burnett JR and Vasikaran SD (2002) Cardiovascular disease and osteoporosis: is there a link between lipids and bone? Ann. Clin. Biochem. 39 (Part 3): 203210

36. Parhami F, Morrow AD, Balucan J, Leitinger N, Watson AD, Tintut $Y$, Berliner JA and Demer LL (1997) Lipid oxidation products have opposite effects on calcifying vascular cell and bone cell differentiation. A possible explanation for the paradox of arterial calcification in osteoporotic patients. Arterioscler. Thromb. Vasc. Biol. 17: 680-687

37. Tintut Y, Saedi B, Saini T, Ariax-Magaloona, Parhami F and Demer LL (2002) Hyperlipidemia enhanced osteoclastic potential of bone-marrow preosteoclasts. J. Bone Miner. Res. 17 (Suppl 1): M261 
38. Luegmayr E, Rodan GA and Reszka AA (2002) Lipoproteins/exogenous cholesterol regulate osteoclast formation and survival. J. Bone Miner. Res. 17 (Suppl 1): F241

39. Mundy G, Garrett R, Harris S, Chan J, Chen D, Rossini G, Boyce B, Zhao M and Gutierrez $G$ (1999) Stimulation of bone formation in vitro and in rodents by statins. Science 286: 1946-1949

40. Johnston Jr CC, Bjarnason NH, Cohen FJ, Shah A, Lindsay R, Mitlak BH, Huster W, Draper MW, Harper KD, Heath 3rd H, Gennari C, Christiansen C, Arnaud CD and Delmas PD (2000) Long-term effects of raloxifene on bone mineral density, bone turnover, and serum lipid levels in early postmenopausal women: three-year data from 2 double-blind, randomized, placebo-controlled trials. Arch. Intern. Med. 160: 3444-3450

41. Rogers MJ (2000) Statins: lower lipids and better bones? Nat. Med. 6: 21-23

42. Toledano JE and Partridge NC (2000) Statins: not just for cholesterol? Trends Endocrinol. Metab. 11: 255-256

43. Ferber D (2000) Osteoporosis: cholesterol drugs show promise as bone builders. Science 288: 2297-2298

44. Ylitalo R (2000) Bisphosphonates and atherosclerosis. Gen. Pharmacol. 35 287-296

45. Tintut Y, Parhami F, Tsingotjidou A, Tetradis S, Territo M and Demer LL (2002) 8-Isoprostaglandin E2 enhances receptor-activated NFkappa B ligand (RANKL)-dependent osteoclastic potential of marrow hematopoietic precursors via the cAMP pathway. J. Biol. Chem. 277: 14221-14226

46. Rothblat GH, de la Llera-Moya M, Atger V, Kellner-Weibel G, Williams DL and Phillips MC (1999) Cell cholesterol efflux: integration of old and new observations provides new insights. J. Lipid Res. 40: 781-796

47. Suc I, Escargueil-Blanc I, Troly M, Salvayre R and Negre-Salvayre A (1997) $\mathrm{HDL}$ and ApoA prevent cell death of endothelial cells induced by oxidized LDL. Arterioscler. Thromb. Vasc. Biol. 17: 2158-2166

48. Sugano M, Tsuchida K and Makino N (2000) High-density lipoproteins protect endothelial cells from tumor necrosis factor-alpha-induced apoptosis. Biochem. Biophys. Res. Commun. 272: 872-876

49. Nofer JR, Levkau B, Wolinska I, Junker R, Fobker M, von Eckardstein A, Seedorf $U$ and Assmann $G$ (2001) Suppression of endothelial cell apoptosis by high density lipoproteins (HDL) and HDL-associated lysosphingolipids. J. Biol. Chem. 276: 34480-34485

50. Matsunaga T, Iguchi K, Nakajima T, Koyama I, Miyazaki T, Inoue I, Kawai S, Katayama S, Hirano K, Hokari S and Komoda T (2001) Glycated high-density lipoprotein induces apoptosis of endothelial cells via a mitochondrial dysfunction. Biochem. Biophys. Res. Commun. 287: 714-720

51. Ishibashi S, Brown MS, Goldstein JL, Gerard RD, Hammer RE and Herz J (1993) Hypercholesterolemia in low density lipoprotein receptor knockout mice and its reversal by adenovirus-mediated gene delivery. J. Clin. Invest. 92: 883-893

52. Parhami F, Watson AD, Dominguez A, Beamer WG, Hama S, Navab M, Drake TA and Wand $X$ (2001) Parallel development of vascular calcification and osteoporosis in hyperlipidemic mice: evidence for the role of lipid oxidation products. J. Bone Miner. Res. 16 (Suppl 1): 1144

53. Ohtani Y, Irie T, Uekama K, Fukunaga K and Pitha J (1989) Differential effects of alpha-, beta- and gamma-cyclodextrins on human erythrocytes. Eur. J. Biochem. 186: 17-22
54. Irie T, Fukunaga K and Pitha J (1992) Hydroxypropylcyclodextrins in parenteral use. I: Lipid dissolution and effects on lipid transfers in vitro. J. Pharm. Sci. 81: $521-523$

55. Greenberg-Ofrath N, Terespolosky Y, Kahane I and Bar R (1993) Cyclodextrins as carriers of cholesterol and fatty acids in cultivation of mycoplasmas. Appl. Environ. Microbiol. 59: 547-551

56. Klein U, Gimpl G and Fahrenholz F (1995) Alteration of the myometrial plasma membrane cholesterol content with beta-cyclodextrin modulates the binding affinity of the oxytocin receptor. Biochemistry $34: 13784-13793$

57. Gimpl G, Burger K and Fahrenholz F (1997) Cholesterol as modulator of receptor function. Biochemistry 36: 10959-10974

58. Green JM, Zhelesnyak A, Chung J, Lindberg FP, Sarfati M, Frazier WA and Brown EJ (1999) Role of cholesterol in formation and function of a signaling complex involving alphavbeta3, integrin-associated protein (CD47), and heterotrimeric $G$ proteins. J. Cell Biol. 146: 673-682

59. Gupta AK and Rudney H (1991) Plasma membrane sphingomyelin and the regulation of HMG-COA reductase activity and cholesterol biosynthesis in cell cultures. J. Lipid Res. 32: 125-136

60. Muir LV, Born E, Mathur SN and Field FJ (1996) Lysophosphatidylcholine increases 3-hydroxy-3-methylglutaryl-coenzyme A reductase gene expression in CaCo-2 cells. Gastroenterology 110: 1068-1076

61. Nordskog BK, Reagan Jr JW and St Clair RW (1999) Sterol synthesis is upregulated in cholesterol-loaded pigeon macrophages during induction of cholesterol efflux. J. Lipid Res. 40: 1806-1817

62. Field FJ, Born E, Murthy S and Mathur SN (2001) Regulation of sterol regulatory element-binding proteins by cholesterol flux in $\mathrm{CaCo}-2$ cells. J. Lipid Res. 42: 1687-1698

63. Fielding CJ and Fielding PE (2001) Caveolae and intracellular trafficking of cholesterol. Adv. Drug Deliv. Rev. 49: 251-264

64. Fuller K, Owens JM, Jagger CJ, Wilson A, Moss R and Chambers TJ (1993) Macrophage colony-stimulating factor stimulates survival and chemotactic behavior in isolated osteoclasts. J. Exp. Med. 178: 1733-1744

65. Boyle WJ, Simonet WS and Lacey DL (2003) Osteoclast differentiation and activation. Nature 423: 337-342

66. Wesolowski G, Duong LT, Lakkakorpi PT, Nagy RM, Tezuka K, Tanaka H, Rodan GA and Rodan SB (1995) Isolation and characterization of highly enriched, prefusion mouse osteoclastic cells. Exp. Cell Res. 219: 679-686

67. Fisher JE, Rogers MJ, Halasy JM, Luckman SP, Hughes DE, Masarachia PJ, Wesolowski G, Russell RG, Rodan GA and Reszka AA (1999) Alendronate mechanism of action: geranylgeraniol, an intermediate in the mevalonate pathway, prevents inhibition of osteoclast formation, bone resorption, and kinase activation in vitro. Proc. Natl. Acad. Sci. USA 96: 133-138

68. Halasy-Nagy JM, Rodan GA and Reszka AA (2001) Inhibition of bone resorption by alendronate and risedronate does not require osteoclast apoptosis. Bone 29: 553-559

69. Reszka AA, Halasy-Nagy J and Rodan GA (2001) Nitrogen-bisphosphonates block retinoblastoma phosphorylation and cell growth by inhibiting the cholesterol biosynthetic pathway in a keratinocyte model for esophageal irritation. Mol. Pharmacol. 59: 193-202 